\title{
Herpes Simplex Reactivation, CTCAE
}

National Cancer Institute

\section{Source}

National Cancer Institute. Herpes Simplex Reactivation, CT CAE. NCI Thesaurus. Code C143212.

A disorder characterized by the reactivation of Herpes simplex virus 